\title{
Studi Awal Solar Water Distiller Air Laut dengan Limbah Botol Plastik untuk Penyediaan Air Bersih
}

\author{
Endarko, ${ }^{*}$ Suasmoro, Triwikantoro, Agus Purwanto, Zaenal Arifin, Mashuri, Yoyok Cahyono, Yanurita Dwi \\ Hapsari, Heru Sukamto, Suminar Pratapa, Herliansyah, Fachrina Maryam, Mira Anjani, dan Niken Rancangkapti \\ Departemen Fisika-FIA, Institut Teknologi Sepuluh Nopember (ITS) \\ Kampus ITS Sukolilo, Surabaya 60111
}

\begin{abstract}
Intisari
Telah berhasil diteliti pemanfaatan limbah botol plastik minum sebagai solar water distiller untuk penyediaan air bersih. Pada penelitian ini botol plastik 600 dan $1500 \mathrm{~mL}$ digunakan untuk solar water distiller dengan 9 variasi. Botol ukuran $600 \mathrm{~mL}$ dengan variasi penambahan kaleng minuman soda yang dicat hitam maupun tidak (3 variasi) sebagai tipe A, botol plastik $600 \mathrm{~mL}$ yang disambungkan dengan botol plastik $1500 \mathrm{~mL}$ dengan posisi berada di atas botol $600 \mathrm{~mL}$ terdapat botol plastik kecil yang ditempatkan didalam botol $1500 \mathrm{~mL}$ dengan variasi baik yang dicat hitam ataupun tidak (3 Variasi) disebut dengan tipe B. Kemudian 3 variasi berikutnya adalah botol $1500 \mathrm{~mL}$ yang dipotong separuh menyerupai wadah terbuka dengan botol plastik yang lebih kecil ditempatkan di dalamnya baik yang dicat hitam maupun tidak (Tipe C). Sebagai pembanding digunakan wadah plastik (baskom) dengan diameter $25 \mathrm{~cm}$. Penelitian menggunakan $30 \mathrm{~mL}$ air laut sebagai data awal, setelah 8 jam dipaparkan dalam panas matahari, hasil menunjukan bahwa wadah plastik mempunyai effisiensi yang lebih baik hingga mencapai sebesar $(55,7 \pm 3,1) \%$, sedangkan untuk sistem distilasi dengan botol plastik, effisiensi tertinggi diperoleh sistem distilasi tipe A dengan jangkauan sebesar 11-13\%. Sementara untuk tipe B dan C berturut-turut sebesar $1-4 \%$.
\end{abstract}

\begin{abstract}
It has been successfully investigated the utilization of waste plastic bottles as a solar water distiller for the provision of clean water. In this study 600 and $1500 \mathrm{~mL}$ plastic bottles used for solar water distiller with 9 variations. A $600 \mathrm{~mL}$ bottle with a variation of the addition of soda cans painted black or not (3 variations) as type A. Hereinafter, $600 \mathrm{~mL}$ plastic bottle connected with $1500 \mathrm{~mL}$ plastic bottle positioned above $600 \mathrm{~mL}$ bottle contained small plastic bottle placed in bottle $1500 \mathrm{~mL}$ with variations of either painted black or not (3 variations) is called type B. Moreover, the next three variations are $1500 \mathrm{~mL}$ bottles cut in half to resemble open containers with smaller plastic bottles placed inside whether painted black or not (Type C). Furthermore, as a comparison of plastic containers (basin) with a diameter of $25 \mathrm{~cm}$ used for the solar distiller. The study was conducted with $30 \mathrm{~mL}$ of seawater as the initial data, after 8 hours exposed to the sunlight. The results showed that plastic containers had better efficiency compared to all types of the plastic bottle as solar distiller with the value up to $(55.7 \pm 3.1) \%$, while for the distillation system with plastic bottles, the highest efficiency was obtained type distillation system A with a range of 11-13\%. While for type B and C respectively equal to $1-4 \%$.
\end{abstract}

KATA KUNCI: plastic bottle, distiller, efficiency, fresh water http://dx.doi.org/10.12962/j24604682.v14i2.3572

\section{PENDAHULUAN}

Indonesia sebagai negara yang terletak di garis katulistiwa dan dianugerahi sinar matahari yang bersinar sepanjang tahun ditambah dengan luas laut yang lebih besar dari daratan menjadikan sumber daya alam ini perlu untuk dimanfaatkan sebesar kesejahteraan masyakat. Pemanfatan air laut sebagai sumber air bersih masih terbatas dikarenakan masih mahalnya sistem yang dapat mengubah air laut menjadi air bersih yang layak dikonsumsi oleh manusia [1].

Distilasi dengan tenaga surya dapat menjadi salah satu pi-

*E-MAIL: endarko@physics.its.ac.id lihan yang dapat diterapkan di Indonesia mengingat energi matahari dapat diperoleh secara mudah dan melimpah sepanjang tahun. Secara umum, prinsip kerja dari distilasi tenaga surya adalah menempatkan air yang berada dalam wadah penampungan kemudian dipanaskan menggunakan sinar matahari sampai menghasilkan uap air. Selanjutnya uap air tersebut akan mengalami pengembunan ketika menyentuh dinding kaca atau penutup dari sistem distilasinya. Sistem distilasi tenaga surya selain mudah dan murah juga mampu menghilangkan kandungan logam-logam berat, organisme mikrobiologi dan garam dalam air [1].

Peneliti sebelumnya yang melaporkan bahwa solar distilasi mempunyai potensi sebagai teknologi alternatif untuk penyedia air. Rada Z. Asadi $d k k$. melaporkan bahwa distilasi dengan tenaga surya pada pengolahan air limbah menghasilkan pengurangan sebesar 93,8 $\pm 1,4 \%$ untuk COD (Chemical Oxygen 


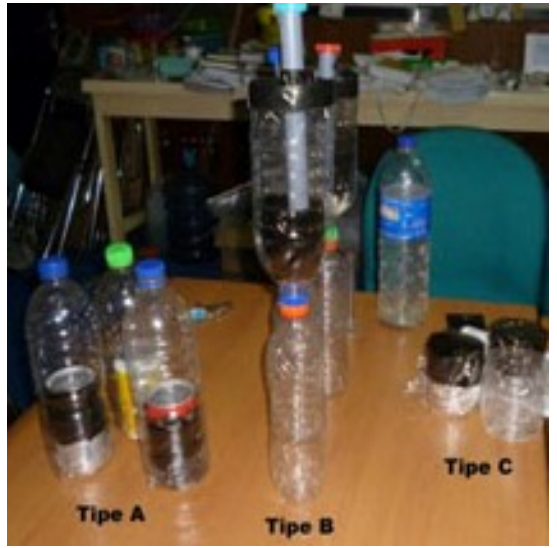

(a)

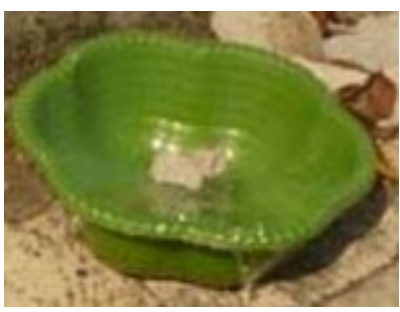

(b)

Gambar 1: Tiga model solar water distiller dengan botol plastik dan 1 model pembanding.

Demand), 94,8 $\pm 2,2 \%$ untuk kekeruhan, $85,7 \pm 12,7 \%$ untuk TSS (Total Suspended Solid), dan 99,3 $\pm 0,5 \%$ dalam hal TDS (Total Disolved Solid) [2].

Sementara itu, Kabeel melakukan analisis biaya untuk 17 desain distilasi dengan tenaga surya [3]. Hasilnya didapat bahwa desain distilasi air dengan tenaga surya untuk tipe atap double slope mempunyai produktivitas air bersih paling tinggi yaitu 1533 dan $1511 \mathrm{~L} / \mathrm{m}^{2}$ untuk tiap tahunnya dengan biaya yang digunakan lebih rendah yaitu 0,0135 dan 0,031 \$/L [3].

Produktivitas sistem distilasi tenaga surya dapat dipengaruhi oleh radiasi matahari, kedalaman air, kecepatan angin, sudut kemiringan dan bahan pelat penutup, suhu lingkungan, bahan dan ketebalan isolator, serta bahan dan luas permukaan bak penampungan [1].

Dalam penelitian ini, limbah botol plastik air minum ukuran 600 dan $1500 \mathrm{~mL}$ akan digunakan sebagai solar water distiller dan air laut sebagai contoh air yang digunakan untuk distilasinya. Desain atau model untuk tipe distilasi akan diteliti guna mencari bentuk yang paling efektif dalam menghasilkan air bersih dari air laut.

\section{METODOLOGI PENELITIAN}

Pada penelitian ini digunakan 9 variasi desain untuk sistem distilasi air laut, seperti terlihat pada Gambar 1, yang dikelompokan menjadi 3 tipe yaitu Tipe A, Tipe B, dan Tipe C. Tipe A adalah botol plastik air minum ukuran $600 \mathrm{~mL}$ yang dipotong bagian bawahnya kemudian dilipat ke arah dalam kemudian di dalamnya diberi kaleng minuman soda ukuran $330 \mathrm{~mL}$ dimasukan ke dalam botol tersebut. Kaleng soda divariasi dengan 3 macam yaitu, dibiarkan tetap warna aslinya, kaleng dicat hitam, kemudian kaleng dicat hitam dan dilapisi dengan alumunium foil.

Untuk tipe B, botol plastik 600 dan $1500 \mathrm{~mL}$ disambung menjadi satu dengan posisi ujung tutup bertemu satu sama lain, kemudian botol plastik $1500 \mathrm{~mL}$ dipotong $\frac{3}{4}$ bagiannya yang diberi pipa untuk memasukan air lautnya yang didalamnya ada potong $\frac{1}{3}$ bagian dari botol $600 \mathrm{~mL}$ yang divariasi

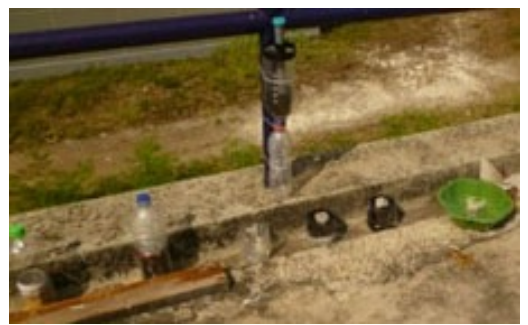

Gambar 2: Proses pengambilan data solar water distiller.

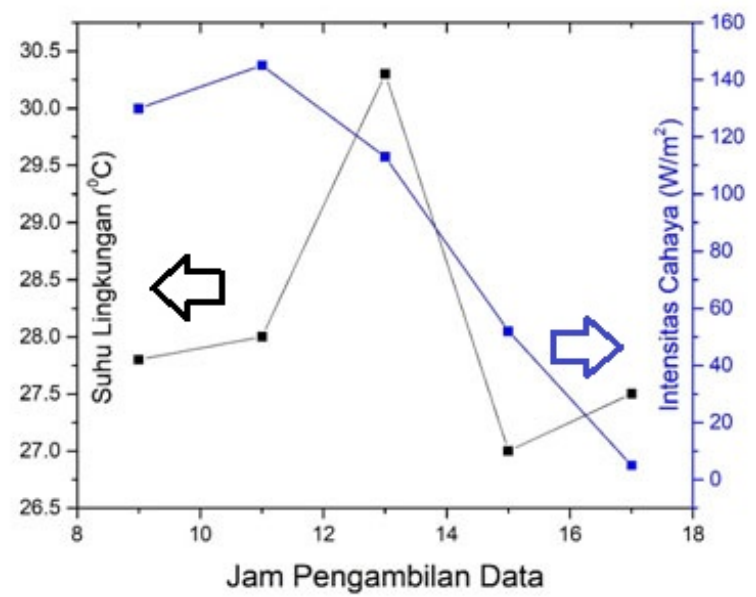

Gambar 3: Data pengukuran suhu dan intensitas cahaya selama proses pengambilan data.

dengan 3 macam yaitu warna aslinya, dicat warna hitam dan dicat warna hitam dan dilapisin aluminum foil. Selanjutnya, untuk tipe $\mathrm{C}$ adalah botol plastik $1500 \mathrm{~mL}$ yang diambil $\frac{1}{3}$ bagian bawahnya kemudian diberi wadah yang lebih kecil untuk dimasukan kedalamnya yang berisi air laut dan kemudian ditutup dengan plastic wrap. Seperti tipe A dan B, botol plastik divariasi menjadi 3 yaitu warna aslinya, dicat hitam, dan dicat hitam serta dilapasi dengan alumunium foil. Sebagai 


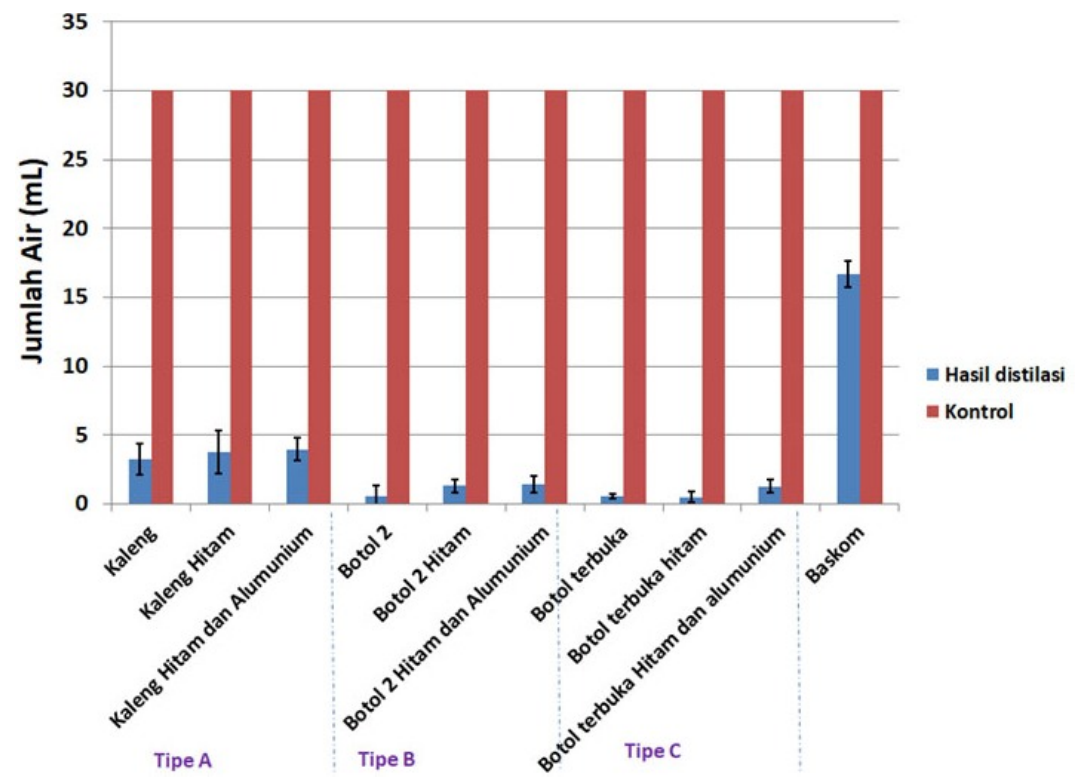

Gambar 4: Hasil distilasi air laut dengan sistem solar water distiller.

pembanding, digunakan wadah plastik (baskom) dengan ukuran $25 \mathrm{~cm}$ yang di dalamnya diberi gelas sebagai penampung hasil distilasinya. Semua percobaan menggunakan air laut sebesar $30 \mathrm{~mL}$ yang diberi perlakuan selama 8 jam di bawah sinar matahari.

\section{HASIL DAN PEMBAHASAN}

Gambar 2 adalah proses pengambilan data yang dilakukan di Black Hole Lantai 2, Departemen Fisika-FIA ITS Surabaya. Percobaan diulang sebanyak tiga kali dan dilakukan pada pukul 09.00-17.00 WIB. Sementara itu untuk hasil pengukuran suhu lingkungan dan intensitas matahari selama proses pengambilan data diukur dengan Thermocouple Digital 4Channel tipe K (HT-9815) [4] dan Solar Power Meter Tenmars TM-206 [5] terangkum dalam Gambar 3. Dari gambar terlihat bahwa suhu tertinggi dicapai saat pukul 13.00 WIB sebesar $30,3^{\circ} \mathrm{C}$ dan yang terendah tercatat saat pukul $15.00 \mathrm{WIB}$ yaitu sebesar $27,5^{\circ} \mathrm{C}$. Sedangkan intensitas cahaya matahari yang tertinggi tercatat adalah sebesar $145 \mathrm{~W} / \mathrm{m}^{2}$ pada pukul 11.00 WIB dan terendah sebesar $5 \mathrm{~W} / \mathrm{m}^{2}$ pada pukul 17.00 WIB.

Hasil distilasi air laut dengan solar water distiller terlihat pada Gambar 4. Pada gambar dapat dianalisis bahwa wadah plastik (baskom) mempunyai effisiensi yang lebih baik dari ketiga model solar water distiller tipe A, B, dan C yang mempunyai nilai hingga mencapai sebesar $(55,7 \pm 3,1) \%$, sedangkan untuk sistem distilasi dengan botol plastik, effisiensi tertinggi diperoleh sistem distilasi tipe A dengan jangkauan sebesar 11-13\%. Sementara untuk tipe B dan C berturut-turut sebesar 1-4\%. Terlihat bahwa solar water distiller dari limbah botol plastik mempunyai peluang sebagai alat distilasi air laut untuk penyedia air bersih.

Bila Tipe A, B, dan C dibandingkan terlihat bahwa sistem distilasi dengan penambahan warna cat hitam dan alumunium foil mempunyai hasil yang lebih baik jika dibandingkan sistem yang lainnya. Hal ini disebabkan, material yang dicat hitam akan meningkatkan emisivitas dari bak penampungan airnya dibandikan dengan material yang berwarna cerah, kemudian aluminium foil bertidak sebagai reflektor dari sistem distilasinya. Hal ini dikuatkan dari hasil penelitian Muftah, $d k k$., pada tahun 2014, yang menyatakan bahwa salah satu parameter yang dapat meningkatkan produktivitas sistem distilasi adalah penggunaan reflektor [6].

Selanjutnya, wadah plastik (baskom) mempunyai efisiensi yang lebih baik, hal ini disebabkan karena kedalaman air dan luas penampang dari bak penampungannya. Bila dibandingkan dengan Tipe A, B, dan C, dengan jumlah air laut yang sama, maka wadah plastik dengan luas permukaan yang lebih besar dan kedalaman airnya yang lebih dangkal sehingga kapasitas penyimpan panasnya akan kecil dan suhu dari air akan menjadi tinggi [7], maka proses penguapan dan pengembunan yang terjadi akan lebih cepat. Secara umum produktivitas sistem distilasi air laut dapat dipengaruhui oleh radiasi matahari [8], kecepatan angin [9], suhu lingkungan [10], kedalaman air [7], dan penambahan reflektor [6].

\section{SIMPULAN}

Studi awal tentang pemanfaatan limbah botol plastik sebagai solar water distiller telah berhasil dilakukan dengan 3 variasi model yaitu Tipe A, B dan C. Dari ketiga model yang telah dibuat dan dianalisa menunjukkan bahwa solar water distiller tipe A mempunyai effisiensi yang lebih tinggi jika dibandingkan dari kedua tipe yang lainnya. Solar water distiller dari limbah botol plastik mempunyai peluang untuk pemenuhan sumber air bersih dari air laut. 
[1] O.A. Kii dan Endarko, "Rancang Bangun Sistem Distilasi Air Laut Tenaga Surya Tipe Double Slope Dengan Penambahan Pelat Absorber Bentuk Gelombang Segitiga Dan Reflektor Internal", Master Thesis, Departemen Fisika-FIA ITS, Surabaya, 2015.

[2] R. Zarasvand Asadi, F. Suja, M.H. Ruslan, and N.A. Jalil, 'The application of a solar still in domestic and industrial wastewater treatment", Sol. Energy, vol. 93, pp. 63-71, Jul. 2013.

[3] A.E. Kabeel, A.M. Hamed, and S.A. El-Agouz, "Cost analysis of different solar still configurations", Energy, vol. 35, no. 7, pp. 2901-2908, Jul. 2010.

[4] HT-9815 Thermocouple thermometers, http://www.xintest. com.cn/ products-detail.php?ProId=25

[5] TM-206_ Solar Power Meter, http://www.tenmars.com/weblsen-us/TM-206.html

[6] A.F. Muftah, M.A. Alghoul, A. Fudholi, M.M. Abdul-Majeed, and K. Sopian, "Factors affecting basin type solar still productivity: A detailed review", Renew. Sustain. Energy Rev., vol. 32, pp. 430-447, Apr. 2014

[7] K. Kalidasa Murugavel, K.K.S.K. Chockalingam, and K. Srithar, "Progresses in improving the effectiveness of the single basin passive solar still", Desalination, vol. 220, no. 1-3, pp. 677-686, Mar. 2008.

[8] R. Dev, S.A. Abdul-Wahab, and G.N. Tiwari, "Performance study of the inverted absorber solar still with water depth and total dissolved solid", Appl. Energy, vol. 88, no. 1, pp. 252-264, Jan. 2011.

[9] A.A. El-Sebaii, "On effect of wind speed on passive solar still performance based on inner/outer surface temperatures of the glass cover", Energy, vol. 36, no. 8, pp. 4943-4949, Aug. 2011.

[10] H. Al-Hinai, M.S. Al-Nassri, and B.A. Jubran, "Effect of climatic, design and operational parameters on the yield of a simple solar still”, Energy Convers. Manag., vol. 43, no. 13, pp. 16391650, Sep. 2002 